\title{
Retrospective study of cases of rupture uterus
}

\author{
Manju Arora ${ }^{1 *}$, Sunita Jindal ${ }^{2}$, Sangeeta Gupta ${ }^{3}$
}

\author{
${ }^{1}$ Department of Obstetrics and Gynecology, Kasturba Hospital, Delhi, India \\ ${ }^{2}$ Department of Obstetrics and Gynecology, ESIC, Basaidarapur, New Delhi, India \\ ${ }^{3}$ Department of Obstetrics and Gynecology, ESIC Medical College and Hospital, New Delhi, India
}

Received: 18 February 2017

Accepted: 24 March 2017

\author{
*Correspondence: \\ Dr. Manju Arora, \\ E-mail: aroradrmanju@gmail.com
}

Copyright: () the author(s), publisher and licensee Medip Academy. This is an open-access article distributed under the terms of the Creative Commons Attribution Non-Commercial License, which permits unrestricted non-commercial use, distribution, and reproduction in any medium, provided the original work is properly cited.

\begin{abstract}
Background: This study aimed to evaluate the risk factors, clinical presentation, management, maternal and perinatal outcome of patients with rupture uterus.

Methods: In this study, clinical records of 14 cases of rupture uterus occurring between January 2001 to August 2004 were reviewed.

Results: During this period 17312 deliveries were conducted and 14 cases of rupture uterus were managed. Incidence of rupture uterus was 0,8/1000 deliveries. In 10/14 (71.4\%) of cases, rupture occurred in scarred uterus (either of cesarean delivery or of any surgery).9/14 (64.2\%) women had rupture of previous cesarean section scar and 4/14 $(28.5 \%)$ women had rupture of unscarred uterus .7/14 (50\%) women had more than one risk factor responsible for rupture uterus. $10 / 14(71.4 \%)$ women were unbooked.10/14 (71.4\%) women had subtotal hysterectomy; $4 / 14(28.5 \%)$ had repair of scar site. Invariably blood had to be transfused in every case per and post-operatively.6/14 (42.8\%) of fetuses could be salvaged; in 7/14 (50\%) women; there was intrauterine death, while another $(7.14 \%)$ woman had preterm neonatal death.

Conclusions: Uterine rupture is a preventable complication. In our study, most of women had no antenatal check-up and/or managed initially by untrained personnel. Antenatal and intranatal care, identification of high-risk cases and education of the people about supervised pregnancy and delivery will reduce the occurrence of uterine rupture.
\end{abstract}

Keywords: Rupture uterus, Maternal and perinatal outcome

\section{INTRODUCTION}

Rupture of pregnant uterus is one of the most serious obstetrical emergencies necessitating prompt diagnosis and management, as it en-dangers the life of both mother and fetus. Rupture of pregnant uterus (scarred/unscarred) may occur at any stage of gestation. It continues to be a common obstetrical hazard in developing countries. In developed countries, with good antenatal care and good supervision during labour, rupture of uterus has become rare except by dehiscence of a caesarean scar.

In India, because of poverty, illiteracy and not easy access to antenatal care, delivery is usually accomplished by untrained midwives, dais or by unqualified doctors; uterine rupture is not uncommon.

Incidence of ruptured uterus varies from $0.6 / 1000$ to 250/1000 deliveries. ${ }^{1}$ Its incidence at a particular institution reflects the level of obstetric care provided in that area.

However, the true incidence of uterine rupture is difficult to ascertain because, the cause of maternal deaths due to obstetric shock in several cases remains obscure. The present study was undertaken to evaluate the risk factors, clinical presentation, management, maternal and perinatal outcome of rupture uterus at our hospital. 


\section{METHODS}

In this retrospective study, clinical records of 14 cases of uterine rupture managed at our hospital during a period 3 $1 / 2$ years (from January 2001 to August 2004) were reviewed.

\section{Inclusion criteria}

Women with history of previous cesarean section in their active phase of labour and in the immediate postpartum period, grand multi-para with good sized fetus (in cephalopelvic disproportion) in labour, any history of uterine surgery (myomectomy - where uterine cavity was opened), previous history of dilatation and curettage with uterine perforation, history of manual removal of placenta, injudicious use of oxytocin during labour, use of vacuum or forceps with scarred uterus.

\section{Exclusion criteria}

Women with unscarred uterus in labour having no cephalo-pelvic disproportion with longitudinal lie.

\section{RESULTS}

A total of 17132 deliveries were conducted and 14 cases of rupture uterus were managed during 3 and a $1 / 2$ year period. Thus the incidence of uterine rupture was $0.8 / 1000$ deliveries. $10(71.4 \%)$ of 14 women were unbooked, 7 $(50 \%)$ of them had no antenatal check-up. $7(50 \%)$ laboured at home and $3(21.4 \%)$ were supervised by untrained personnel. The risk factors in these cases are shown in Table 1 . In majority $10(71.4 \%)$ of cases uterine rupture occurred in women with previous scar, $9(64.2 \%)$ out of 14 women had rupture of previous caesarean scar site; two amongst these nine $(14.2 \%)$ women had rupture of previous classical caesarean section one $(7.1 \%)$ woman had spontaneous rupture at 20 weeks of gestation at uterine fundus. The latter had difficult manual removal of placenta by dai during her last delivery and also had dilatation and curettage for retained products of conception. Out of these
$9(64.2 \%)$ women with previous caesarean scar, 1 (7.1\%) woman had spontaneous rupture at 30 weeks of gestation; $1(7.1 \%)$ had rupture following vacuum delivery. $7 / 14$ $(50 \%)$ women had more than one risk factor responsible for rupture uterus.

Table 1: Risk factors.

\begin{tabular}{|lll|}
\hline Risk factor & No. & Percentage \\
\hline Scarred uterus & 10 & 71.4 \\
\hline Unscarred uterus & 4 & 28.5 \\
\hline Multiple factors & 7 & 50 \\
\hline $\begin{array}{l}\text { Injudicious use of oxytocin } \\
\text { by untrained personnel }\end{array}$ & 3 & 21.4 \\
\hline Previous cesarean & 9 & 64.2 \\
\hline Multiparity & 2 & 14.2 \\
\hline Transverse lie in labour & 1 & 7.14 \\
\hline $\begin{array}{l}\text { Manual removal of } \\
\text { placenta followed by D+C }\end{array}$ & 1 & 7.14 \\
\hline $\begin{array}{l}\text { Scar of previous surgery } \\
\text { Vacuum delivery }\end{array}$ & 1 & 7.14 \\
\hline $\begin{array}{l}\text { Cephalopelvic } \\
\text { disproportion }\end{array}$ & 1 & 7.14 \\
\hline $\begin{array}{l}\text { Prolonged second stage of } \\
\text { labour }\end{array}$ & 1 & 7.14 \\
\hline Unknown cause & 1 & 7.14 \\
\hline
\end{tabular}

Rupture of unscarred uterus occurred in 4 (28.6\%) of cases. In 3 (21.4\%) women, the labour was supervised by untrained personnel. Of these, 1 (7.1\%) woman was multiparous and had cephalo-pelvic disproportion.

Table 2: Time of rupture.

\begin{tabular}{|lll|}
\hline Time of rupture & No. & Percentage \\
\hline Antenatal period & 3 & 21.4 \\
\hline Intrapartum & 9 & 64.2 \\
\hline Immediate postpartum & 1 & 7.14 \\
\hline
\end{tabular}

Another had normal vaginal delivery with postpartum haemorrhage; was diagnosed to have rupture uterus at other referral hospital.

Table 3: Type and number of prior CS of the scarred uterus patients.

\begin{tabular}{|lllll|}
\hline Prior section & No. of caesarean & No. of patient & Percentage \\
\hline \multirow{2}{*}{ Low transverse scar } & 1 & 6 & 42.8 & 42.8 \\
\cline { 2 - 6 } & 2 & 1 & 7.14 & 7.14 \\
\hline Classical Scar & 1 & 1 & 7.14 & 7.14 \\
(1 LTS, 1 classical scar) & 1 & 1 & 7.14 & 7.14 \\
\hline
\end{tabular}

The clinical features were quite variable and most of the women presented with more than one feature. The clinical presentation is tabulated in Table 4. All women underwent surgical exploration after initial resuscitation. The surgical management depended upon the parity, extent of uterine rupture and general condition of the women. The details of the surgical procedures followed are shown in Table 5. Maternal and perinatal outcome are shown in Table 7. 
Table 4: Clinical features.

Clinical features

Pain abd: BPV: uterine tenderness

BPV: Superficial fetal parts: absent fetal heart sounds

Tachycardia, absent fetal heart sounds: pallor

Shock: pallor: low volume pulse: abdominal: distension

Shock: hypotension: unconsciousness

Scar tenderness and hypotension

Bleeding PV: absent fetal heart sounds: uterine tenderness

Shock: scar tenderness: fetal distress

Haematuria

Booked

Unhooked

1
2
2
2
1
1
2
1
1
4
10

Table 5: Surgical management.

\begin{tabular}{|lll|}
\hline Repair alone & $\begin{array}{l}\text { Searred } \\
\text { uterus }\end{array}$ & $\begin{array}{l}\text { Unscarred } \\
\text { uterus }\end{array}$ \\
$\begin{array}{l}\text { Repair with tubal } \\
\text { ligation }\end{array}$ & 3 & \\
\hline Hysterectomy & 1 & \\
\hline
\end{tabular}

Table 6: Site of rupture.

\begin{tabular}{|l|l|}
\hline Site of rupture & No. of Patients \\
\hline Fundal & 3 \\
\hline Posterior & 1 \\
\hline Lateral & 2 \\
\hline Involving cervix/vagina & 1 \\
\hline Upper anterior wall & 2 \\
\hline $\begin{array}{l}\text { Lower anterior wall with upper } \\
\text { extension }\end{array}$ & 5 \\
\hline
\end{tabular}

Table 7: Maternal and fetal outcome.

\begin{tabular}{|lll|}
\hline Maternal morbidity & $\begin{array}{l}\text { Number of } \\
\text { patients }\end{array}$ & Percentage \\
\hline Anaemia & 10 & 71.4 \\
\hline Puerperal sepsis & 4 & 285 \\
\hline Bladder injury & 2 & 14.2 \\
\hline Fetal outcome & & \\
\hline Still birth & 7 & 50 \\
\hline Neonatal death & 1 & 7.14 \\
\hline Live birth & 6 & 42.8 \\
\hline
\end{tabular}

All women required blood transfusion. Associated bladder rupture was repaired in two cases $(14.2 \%)$. After excluding fetal wastage before the age of viability, perinatal mortality was $57.1 \%(8 / 14)$.

In $7 / 14(50 \%)$ women: there was intrauterine death: while another $(7 \%)$ had preterm neonatal death. None of the fetuses found in peritoneal cavity following rupture of uterus was alive, whereas six (42.8\%) intrauterine fetuses survived.

\section{DISCUSSION}

Rupture uterus continues to be an important obstetrical emergency in developing countries. Its incidence varies from 1:149 to $1: 2966^{2}$ and in our study, it was $1: 1223$. Our hospital primarily caters to poor, illiterate, labour class personnel and also complicated cases from peripheral hospitals are referred here. Obstetrical practice has changed considerably with the availability of antibiotics, reduction in maternal risk from surgery, resulting in increased number of primary and repeat caesarean sections. In our study, rupture from scarred uterus occurred in 10 women $(71.4 \%)$, out of these 9 women $(64.2 \%)$ had rupture of previous caesarean scar, 2 women $(14.2 \%)$ had rupture of previous classical caesarean and 1 (7.14\%) from scar of previous D and C. The results of present study are consistent with those of Rachagan et al 1991. ${ }^{2}$ Rupture of LSCS scar mostly occur when women are allowed to undergo induction of labour than spontaneous labour, as evident from a study of Ravasia et al; where the uterine rupture rate with induced trial of labour (1.4\%) was significantly higher than with a spontaneous trial of labour $(0.45 \%) .^{3}$ Moreover, women who experience failed vaginal birth after cesarean have higher risks of uterine rupture $(2.5 \%)$ as compared with women who have successful vaginal birth after cesarean $(0.1 \%)$ Landon MB et al. ${ }^{4}$

Rupture of a previous caesarean section scar is a matter of great concern. According to Dewhrust, scar rupture in patients with previous classical caesarean section was $2.2 \%$ of all pregnancies reaching viability, $4.7 \%$ when women were allowed to labour and $8.9 \%$ when vaginal delivery occurred. The similar rates for lower segment were $0.5 \%, 0.8 \%$ and $1.2 \%$ respectively. ${ }^{5}$ Risk of uterine rupture in women with T-Shaped uterine incision is 4-9\%; with low vertical it is $1-7 \%$., women with a prior vertical incision in lower uterine segment without fundal extension may be candidate for VBAC (ACOG 2004). In women with previous LSCS, for deciding mode of delivery, the primary indication for and type of previous caesarean section must be meticulously screened, the integrity of the 
scar to be assessed and cephalo-pelvic disproportion to be ruled out so as to avoid rupture uterus.

Rupture of uterine scar of previous perforation during Dilatation and Curettage is unusual. This may be because of under reporting of such cases. In our study, one woman $(7.14 \%)$ had rupture subsequent to rupture of scar of manual removal of placenta and dilatation and curettage. Similarly, Taylor et al reported a uterine rupture in a primigravida with history of uterine perforation during a prior Laproscopy. ${ }^{6}$ Risk of spontaneous uterine rupture in multiparous women with morbidly adherent placenta has been documented. ${ }^{6}$ Recently uterine rupture secondary to Ehler- Danlos syndrome (genetically determined disorder of connective tissue) has been reported which was previously thought to be idiopathic.

Short interpregnancy internal of less than 6 months is an independent risk factor for uterine rupture and major maternal morbidity in patients who attempt VBAC, increasing morbidity rate two-fold to three-fold.' (Stamilio et al Compared with a double layer closure, a single layer closure of the primary cesarean may increase the risk of uterine rupture 4-fold during a subsequent trial of labour Bu Joed E et al. ${ }^{8}$

Grand multi-parity is another important risk factor for uterine rupture. With each successive pregnancy, the risk of uterine rupture increases. Rupture in these grand multiparity is because of evident uterine contractions against obstruction rather than increased proportion of fibrous tissue in uterine wall with successive pregnancies. Multiparity in two women (14.2\%) was a risk factor for rupture uterus in present study as in contrast to the findings of Eden et al who reported that $83.3 \%$ cases of rupture uterus occurred in multiparas with unscarred uterus. ${ }^{9}$

Uterine rupture appears to be uncommon with vacuum extraction, one woman $(7.14 \%)$ had uterine rupture following application of vacuum. Vacuum extraction was done after fulfilling all the requisites and after excluding cephalopelvic disproportion to cut short second stage of labour in a woman with previous caesarean section. The presence of a dehiscent or weak uterine scar could conduce to uterine rupture with vacuum extraction and this appears to be a possible cause as suggested by Fahmyetal. ${ }^{10} \mathrm{He}$ reported an incidence of 1:1038 of uterine rupture following vacuum extractions.

The risk of uterine rupture or dehiscence from a defective scar is directly related to the degree of lower uterine segment thinning measured sonographically at or around 37 weeks. This risk increases significantly when the thickness is $3.5 \mathrm{~mm}$ or less. ${ }^{11}$

The decision to perform uterine repair or hysterectomy in cases of uterine rupture is influenced by the parity of the patient, extent of the rupture and general condition of the patients. Repair of the uterine rupture should be performed in women with scar rupture in whom the tear is most often linear. If done without tubal ligation, the possibility of recurrence of rupture or dehiscence in subsequent pregnancy remains. ${ }^{12}$ Thakur et al evaluated outcome in women undergoing subtotal hysterectomy versus repair in extremes of uterine rupture. ${ }^{13}$ They found that the maternal mortality was significantly higher in women who underwent repair (46\% vs 20\%). Megafu observed that subtotal hysterectomy resulted in better maternal salvage and attributed higher maternal mortality and morbidity after repair, to spreading infection from infected uterus and longer time required for repair of complex rupture. ${ }^{14}$

The most effective way of management of a case of rupture uterus is correction of fluid and blood loss followed by laparotomy and subtotal hysterectomy. This method gave a lower mortality than either repair and sterilization or total hysterectomy. Adequate preoperative resuscitation, experience of the surgeon and time interval between rupture and operation also influences mortality rate. ${ }^{11}$ Lower maternal morbidity in our hospital could be due to early presentation, availability of blood transfusion and round the clock services of competent anaesthetist and obstetrician resulting in prompt management.

Fetal loss in uterine rupture varies from $0 \%{ }^{15}$ to $32.4 \% .2$ Peritoneal cavity is not conducive to fetal survival. None of the fetuses lying into the peritoneal cavity following uterine rupture could be salvaged in the present series. Overall perinatal mortality rate was $8 / 14(57.1 \%)$.

In the present study, a majority of uterine ruptures i.e. $71.4 \%$ was associated with scarred uterus. Most of the women had no antenatal check-up and/or were managed initially by untrained personnel. Thus, in most of the cases, uterine rupture is a preventable complication. Antenatal and intranatal care, identification of high risk cases and education of the people about supervised pregnancy and delivery will reduce the occurrence of uterine rupture.

\section{CONCLUSION}

Doppler sonography is an indispensable tool in evaluating pregnancies complicated with uteroplacental insufficiency. This study showed that of all the fetal Doppler parameters, umbilical artery-S/D ratio and umbilical artery-RI $>2 \mathrm{SD}$ are significant predictors of adverse perinatal outcome like perinatal deaths and immediate resuscitation. Umbilical artery-PI $>2$ SD was predictive of acute fetal distress in labour but on multivariate analysis failed to find any association. None of the Doppler parameters helped to predict neonatal nursery admission. Thus, Doppler parameters can help the obstetrician and neonatologist to plan delivery and minimize adverse perinatal outcomes.

\section{ACKNOWLEDGEMENTS}

Authors would like to thank their seniors Dr. Neelima Kapoor-Ex-Head of Department of Obstetrics and gynaecology at ESIC Hospital, Dr. Chayya Gupta, Dr. 
Sharda Sethi, Dr. Satinder Kaur, for carrying out this study and managing such patients.

Funding: No funding sources Conflict of interest: None declared

Ethical approval: The study was approved by the Institutional Ethics Committee

\section{REFERENCES}

1. WHO systematic review of maternal mortality and morbidity: The prevalence of uterine rupture. BJOG. 2005;112:1221-8.

2. Rachagan SP, Raman S, Balasundram G, Balakrishnan S. Rupture of the pregnant uterus - 21year review. Aust NZJ Obstet Gynecol. 1999;31:3740.

3. Ravasia DJ, Wood Stephen L, Pollard Jeffery K. Uterine rupture during induced trial of labour among women with previous cesarean delivery. Am J Obstractgynecol. 2000;183:1176-9.

4. London MB, Hawth JC, Leveno KJ, Spong CY, Leintecker S, Varner MW, et al. Maternal and perinatal outcomes associated with a trial of labour prior cesarean delivery. National Institute of Child health and humon development maternal-fetal medicine units. Network $\mathrm{N}$ End J Med. 2004;351:2581-9.

5. Dewhurst CJ. The ruptured caesarean section scar. J Obstet Gynaecol Br Emp. 1957;64(1):113-8.

6. Walsh CA, Baxi LV. Rupture of the primigravid uterus: a review of literature. Obstetrical Gynecol Survey. 2007;62:327-34.
7. Stailio DM, Defrancosmily, Emmanuelte P, Odibo A, Peipert JF, Allsworth JE. Short interpregnancy interval. Risk of uterine rupture and complications of vaginal birth after cesarean delivery. Obstet Gynecol. 2007; 110:1075-82.

8. Bajald E, Bujold C, Hamilton EF, Harel F, Gavthier RJ. The impact of a single layer or double layer closure on uterine rupture. Am J Obstet Gynecol. 2002; 186:1326-30.

9. Eden RD, Parker RT, Gall SA. Rupture of the pregnant uterus. A 35 year review. Obstet Gynecol. 1986;68:671-4.

10. Fahmy K. Uterine rupture and vacuum extraction. Int J Gynecol Obstet. 1976;14:509-12.

11. Rozenberg P, Goffinet F, Phillippe HJ, Nisand I. Ultrasonographic measurement of lower uterine segment to assess risk of defects of scarred uterus. The Lancet. 1996;347:281-4.

12. Aguero O, Kizer S. Suture of the uterine rupture. Obstet Gyneol. 1968;31:806-10.

13. Thakur A, Heer MS, Thakur V. Subtotal hysterectomy for uterine rupture. Int J Gynecol Obstet. 2001;74:2933.

14. Megafu U. Factors influencing maternal survival in ruptured uterus. Int J Gynecol Obstet. 1985;23:47580.

15. Fedorkow DM, Nimrod CR, Taylor PJ. Ruptured uterus in pregnancy: A Canadian Hospital's experience. Can Med Assoc J. 1987;137:27-9.

Cite this article as: Arora M, Jindal S, Gupta S. Retrospective study of cases of rupture uterus. Int J Reprod Contracept Obstet Gynecol 2017;6:1900-4. 